Cahiers de recherches médiévales

\title{
De Proprietatibus Rerum
}

Versiones castellanas

María Nieves Sánchez González de Herrero

\section{(2) OpenEdition}

\section{Journals}

Edición electrónica

URL: https://journals.openedition.org/crm/11072

DOI: $10.4000 / \mathrm{crm} .11072$

ISSN: 1955-2424

Editor

Honoré Champion

Edición impresa

Fecha de publicación: 10 diciembre 2008

Paginación: 349-366

ISSN: 1272-9752

Referencia electrónica

María Nieves Sánchez González de Herrero, «De Proprietatibus Rerum», Cahiers de recherches

médiévales [En línea], 16 | 2008, Publicado el 15 diciembre 2011, consultado el 15 diciembre 2022.

URL: http://journals.openedition.org/crm/11072 ; DOI: https://doi.org/10.4000/crm.11072

All rights reserved 


\section{酷M}

\section{De Proprietatibus Rerum : Versiones castellanas}

Abstract: The main purpose of this essay is to describe the two medieval Spanish versions, which have survive until today, of the work De Proprietatibus Rerum by Bartholomaeus Anglicus. The reason is that both of them are not well-known versions of one of the most widely used encyclopedias in Western Europe during the Middle Ages. The article consists of a brief presentation of the contents of both, followed by an explanation of their most remarkable linguistic features, which will let us distinguish two linguistic varieties from a diatopic point of view; it concludes with a revision of the main features of the translations, that were based on different source texts, from Latin in one case and from French and Latin in the other, and that were also composed in different dates, which determines, at least in part, their technique and quality.

Résumé : Le propos de cet exposé est de décrire les deux versions médievales castillanes qui ont survécu jusqu'à nos jours de l'oeuvre de Bartholomceus Anglicus De Proprietatibus Rerum. Sa raison d'être est que l'on a en face de nous deux versions peu connues d'une des encyclopédies les plus diffusées dans l'occident européen au Moyen Âge. Dans cet article, on trouvera une présentation succincte du contenu de chacune d'elles, suivie d'un exposé des caractéristiques linguistiques les plus remarquables des deux textes, ce qui permettra de parler de deux variantes linguistiques du point de vue diatopique; l'on terminera par une révision des caractéristiques des traductions élaborées à partir de différentes sources, soit uniquement le latin, soit le français et le latin, et ceci à différentes dates, ce qui conditionne, du moins en partie, la technique et la qualité du texte.

De Proprietatibus Rerum, obra de Bartolomé Ánglico, fue una de las enciclopedias medievales más difundidas por la Europa Medieval ${ }^{1}$, de modo que no

\footnotetext{
${ }^{1}$ Sobre la vida del autor, de la que se sabe poco, y sobre la obra en sí, cf. la Introducción General de B. Van Den Abeele en Bartholomæus Anglicus, De Proprietatibus Rerum, t. I, Prohemium, Libri I-IV, Turnhout, Brepols, 2007, p. 3-21. Sobre el enciclopedismo medieval, pueden verse, entre otros, S. Auroux, «La notion d'encyclopédie philosophique», L'encyclopédisme, Actes du colloque de Caen, 12-16 janvier 1987, A. Becq (dir.), París, Klincksieck, 1991, p. 125-143. J. Le Goff, «Pourquoi le XIII ${ }^{\mathrm{e}}$ siècle a-t-il été plus particulièrement un siècle d'encyclopédisme?", L'Enciclopedismo Medievale. Atti del Convegno L'Enciclopedismo Medievale. San Gimignano 8-10 ottobre, 1992, a cura di M. Picone, Ravenna, Longo Editore, 1994, p. 23-40. B. Ribémont, «Around the definition of an encyclopedic genre in the Middle Ages », Premodern encyclopaedic texts, ed. P. Binkley, Brill, Leiden/New York/Köln, 1997, p. 47-61; id., Les Origines des encyclopédies médiévales. D'Isidore de Séville aux Carolingiens, Paris, Champion, Bibliothèque du Moyen Âge, 2001; id.,La "Renaissance» du XII siècle et l'Encyclopédisme, París, Honoré Champion, 2002, p. 64-65. B. Beyer de Ryke, «Le miroir du monde: un parcours dans l'encyclopédisme médiéval », Revue Belge de Philologie et d'Histoire 81, 2003, p. 1243 1275, Texte intégral, http://dev.ulb.ac.be/philo/urhm/pdf/miroir.pdf. Las investigaciones
}

Cahiers de Recherches Médiévales, 15, 2008 
sorprende que se hicieran dos traducciones independientes al castellano en la Baja Edad Media. La duplicación o multiplicación de traducciones, incluso coetáneas, de una misma obra fue un hecho bastante frecuente en el proceso de vernacularización medieval ; las causas fueron diversas, desde el desconocimiento de la existencia de otra u otras versiones hasta la valoración crítica y el desacuerdo con el estilo de las existentes. Cualquiera de las dos razones parece aceptable en el caso que nos ocupa ; la primera de las dos traducciones desde el punto de vista cronológico, anónima, se ha conservado en un solo manuscrito medieval, lo que podría indicar que no gozó de gran difusión; si pensamos que la traducción castellana de otra enciclopedia medieval, la del Livre dou Tresor de Brunetto Latini, nos ha llegado en doce manuscritos medievales completos ${ }^{2}$, la deducción no parece muy aventurada, aun admitiendo que el azar ha desempeñado un papel importante en los procesos de transmisión ; por otro lado, la calidad de la traducción, al menos la de la versión que nos ha llegado en este único manuscrito ${ }^{3}$, no es especialmente buena y plantea problemas de lectura en más de una ocasión, lo que tampoco es extraño en la época; como señala Lluís Cifuentes, «En definitiva, els traductors, la majoria de les vegades anònims, sabien que, malgrat tots els defectes, vendrien els seus productes, sobretot tenint present que molts dels seus clients tampoc no és que fossin gaire doctes en les matèries traduïdes $»^{4}$.

La más conocida de las dos traducciones es la de fray Vicente de Burgos, que nos ha llegado en edición de Enrique Mayer, Tolosa, 1494, de la que se conservan varios ejemplares. La Biblioteca Nacional de Madrid guarda doce incunables de esta versión completa, que consta de 320 hojas $^{5}$, y uno, de distinta edición (Zaragoza, Pablo Hurus, c. 1495), que consta de 38 hojas y contiene el Tratado de las piedras y metales $^{6}$, prueba de que algunos de los libros que componen la totalidad de la obra circularon como tratados independientes. Hay ejemplares de la edición del texto completo en otras bibliotecas, españolas y americanas?. El traductor partió de la versión francesa de Jean Corbechon, siguió su estructura y ordenamiento, pero utilizó también un texto latino para añadir aclaraciones y comentarios etimológicos

necesarias para desarrollar este trabajo han sido financiadas en parte por la Junta de Castilla y León a través de la ayuda SA105A07.

${ }^{2}$ M. N. Sánchez, «Trasladar del francés al castellano en el siglo XIII. El Libro del Tesoro », Revista de Filología Española LXXXVI, 2006, p. 395.

${ }^{3}$ Hablar de la traducción cuando desconocemos el proceso de transmisión de un texto, e incluso de qué original partió el traductor, como en este caso, es aventurado, pero la comparación del texto contenido en el único manuscrito conservado con fuentes latinas permite establecer razonablemente algunas hipótesis; con un solo testimonio, copia del XV de un texto que desde el punto de vista lingüístico parece anterior, no hay más alternativa que las hipótesis razonables.

${ }^{4}$ Ll. Cifuentes, La ciència en català a l'Etat Mitjiana $i$ el Renaixement, Barcelona, Publicacions i Edicions de la Universitat de Barcelona, 2006, p. 73.

${ }^{5}$ Son los siguientes : I-226, I-441, I-447, I-594, I-747, I-894, I-914, I-1590, I-1688, I-1884, I2259 e I-2386.

${ }^{6} \mathrm{I}-554$.

${ }^{7}$ Dos que conozco y he manejado se hallan en la Biblioteca de la Universidad de Salamanca y en la Hispanic Society de Nueva York. 
que no estaban presentes en el francés ${ }^{8}$. El tratado contiene al principio una tabla o índice, el prólogo del autor y diecinueve libros, los mismos que los textos latino y francés. La tabla, a tres columnas, empieza en el folio 1 y termina en el 6 recto ; al final de este folio comienza, en una sola columna, el prólogo, que ocupa también el seis vuelto; a partir del siete y hasta el trescientos veinte se desarrollan los diecinueve libros, a dos columnas. La obra concluye con una breve recapitulación, el índice de autoridades y las referencias al traductor y a la edición :

Fenece el libro De las Propiedades de las Cosas, trasladado de latín en romance por el reverendo padre fray Vincente de Burgos; emprimido en la noble cibdad de Tolosa por Henrique Meyer de Alemaña, a honor de Dios y de Nuestra Señora y al provecho de muchos rudos e inorantes. Acabóse en el año del Señor de mil y cuatrocientos e noventa cuatro, a diez y ocho del mes de setiembre (fol. 320v).

Una traducción anterior y diferente se conserva en el manuscrito 30037 de la British Library ${ }^{9}$, anónima e incompleta. Si constó el nombre del traductor, se perdió, pues el manuscrito termina en el folio $283 \mathrm{v}$, muy cerca del final ; pero no es esta la única falta de texto, pues, además de amplias reducciones y posibles saltos deliberados por parte del traductor o incluso de algún copista (desconocemos el proceso de transmisión del texto), faltan folios en varias ocasiones a lo largo de la obra.

Al hablar de amplias reducciones, me refiero a ejemplos como los siguientes : el libro I empieza con las propiedades de la divina esencia, que corresponden al capítulo XVI del texto latino; un poco más adelante, del capítulo IV salta al V del libro tercero. En el libro VI se omiten varios capítulos con relación a las versiones latina y de fray Vicente de Burgos, entre ellos los Del varón, Del padre, Del buen y mal señor, Del buen servidor y Del mal siervo. En el libro VII, De las enfermedades, tras un capítulo VII, De la olvidanza, salta varios ; y tras el capítulo $\mathrm{XV}$, que trata de las enfermedades de los ojos, pasa directamente a la ceguedat, omitiendo los De la nube del ojo, La sangre, Las lágrimas y otro general sobre La privación de la vista, a los que dedica unas pocas líneas en el mismo capítulo XV, sin desarrollarlos después. En el libro VIII, reduce los capítulos Del cielo cristalino y Del empíreo a una sola línea al final del capítulo tercero y salta el Del éter; omite después el capítulo general De los círculos del cielo, abre capítulo para Aries y Taurus y en este incluye los signos del Zodiaco restantes. En el libro X, reduce el primer capítulo sobre la materia y salta el segundo, sobre la forma; tras el fuego, salta varios capítulos relacionados con él, como los Del humo, La brasa, La centella, Las sobras de la llama y La ceniza, y pasa directamente al viento, que debería ir tras

\footnotetext{
${ }^{8}$ Cf. M. N. Sánchez y E. Jiménez, «El proceso de la traducción castellana de fray Vicente de Burgos del De Proprietatibus Rerum a partir del análisis léxico», Actas del I Congreso Internacional de la SEMYR, celebrado en Salamanca en diciembre de 2006 (en prensa), y ver más adelante el apartado dedicado a la traducción.

${ }^{9}$ La descripción del catálogo en línea de la British Library es la siguiente : El Libro de Proprietatibus Rerum: a Spanish translation of the work of Bartholomew de Glanville. Imperfect in various places. Paper, the outer leaves of the quires vellum; ff. 283, XV th cent. Large Quarto.
} 
un capítulo dedicado al aire; también falta el capítulo De la gota de lluvia, que debería ir entre los De la lluvia y De la helada. En el libro XIII, mientras la edición latina y la traducción de fray Vicente de Burgos, al tratar de los ríos de la Sagrada Escritura, dedican un capítulo a cada uno de ellos, aquí se enumeran y describen todos juntos a lo largo del capítulo IV, que lleva por título De diversos nombres de ríos; lo mismo sucede en el capítulo siguiente, De los lagos, en el que se incluye el del lago Tiberiades. En el libro XV faltan los capítulos De Bactria y De Bizacena; en el capítulo XXIX, dedicado a Boemia, se añade al final, sin indicación de título, el De Brabancia, y de aquí el texto pasa directamente a Caldea, omitiendo los De Borgoña y Capadocia; tras el De Cedar, pasa a Cananea, omitiendo los De Cancia y De Cantabria; en el folio 124, en la primera columna, en el capítulo De Media enlaza directamente, sin ninguna marca ni señal, con el capítulo, ya empezado, $D e$ Noruega, lo que puede atribuirse a la falta de un folio del testimonio que se copiaba o traducía; omite finalmente el capítulo de los sármatas y el dedicado a la isla De Ténedos. A partir de aquí las omisiones de capítulos disminuyen, no así las reducciones. En el libro XVI, no coloca en el lugar que le corresponde el capítulo III, dedicado al alabastro, pero un poco más adelante une los dedicados a la plata y al argento vivo recuperando en el octavo el Del alabastro, y omite el capítulo De Gleba. En el XVII falta el de la Genesta o Hiniesta. En el libro siguiente, De los animales, tras el capítulo del cordero, omite los De agno anniculo y De agna; tras el Del buey, salta el dedicado al vaquero; no tiene capítulo aparte para el potro, pero añade unas líneas al De la yegua ${ }^{10}$. El último libro, el XIX ${ }^{11}$, omite el capítulo XXI, De colore indico, $\mathrm{y}$, como al llegar al final de los colores, va dos capítulos por detrás de la versión latina, acomoda el último dividiéndolo en tres.

En ocasiones está claro que el traductor evita fragmentos que podían resultarle difíciles desde el punto de vista técnico y lingüístico, como la explicación del embolismo, en el capítulo cuarto del libro VIII, que ni nombra.

Además están las faltas de folios, varias a lo largo del manuscrito; por ejemplo, faltan folios entre el 48 y el 49 , pues va del capítulo VII del libro VII, De las Enfermedades, al final del XII ; de hecho en el folio siguiente se conserva una numeración, que se mantiene a lo largo de los siguientes cien folios, en la que aparece un 85 que se ha tachado y lleva escrito debajo 49, que es el número que corresponde como continuación; en los siguientes cien folios, se ha tachado también y se ha numerado debajo; vuelven a faltar entre el 58 y el 59, pasando del final del capítulo XLIII al LIV, ya comenzado. Tras el folio 66, en el que trata Del Sol, capítulo $\mathrm{XV}$, faltan folios, los que incluirían los capítulos De la Luna y sus

\footnotetext{
${ }^{10}$ Hace lo mismo, es decir unifica, en otros capítulos en los que la versión latina separa macho y hembra, o incluso alguna parte del mismo, como la trompa del elefante; en algunos coincide con la versión de fray Vicente de Burgos, que a su vez toma la reducción de la traducción francesa.

${ }^{11}$ En el comienzo del libro De los Animales, que es el XVIII, la rúbrica marca que es el XIX, y quizá por eso el último está sin inicio de libro ; tampoco hay rúbricas en los ocho primeros capítulos, es decir no se llenaron los vacíos dejados para este fin ; los capítulos como tales no se corresponden exactamente con la versión latina, pues el traductor reunió algunos y dividió otros, hasta marcar la rúbrica del capítulo IX, Del candor, que se corresponde con el final del $\mathrm{X}$ en la versión latina.
} 
propiedades, De la Cabeza y la Cola del Dragón, De las cometas y parte del De las Estrellas fijas, pues el folio 67 se inicia a mitad de dicho capítulo, que es el XX de la obra. En el libro XII, que trata de las aves, entre el folio 84 y el 85 falta uno que contendría casi todo el capítulo segundo, Del águila, y el tercero, Del halcón, pues el 84 termina con el comienzo del capítulo segundo y el 85 empieza al final del tercero; hay un nuevo salto entre los folios 94 y 95, el 94 termina casi al final del capítulo Del avestruz y el 95 comienza en el capítulo primero, ya comenzado, del libro siguiente; faltan pues, en el libro de las aves, los capítulos completos De la tórtola, Del buitre, Del mochuelo, De la abubilla y Del murciélago. El libro XIII se inicia con el capítulo primero ya empezado, en el folio $95 \mathrm{r}$; hay otro salto entre los folios 104 y 105, pues el 104 termina a la mitad del capítulo De los peces y el 105 se inicia ya en el capítulo segundo del libro siguiente, el XIV. En el libro XV faltan algunos folios entre los actuales 114 y 115, de modo que pasamos de la mitad del capítulo XII a la mitad del XXIV; el folio 124 termina con la rúbrica del capítulo De Narbona, pero el 125 empieza con el De Paraíso Terrenal ya muy avanzado. Al final vuelven a faltar folios, quizá uno solo, pues el último, 283, acaba en el capítulo CXLVI incompleto, que trata Del número o proporción sesquialtera, cuando falta únicamente el que sirve de conclusión en la versión latina, llamado Recapitulación en la de fray Vicente de Burgos ; en la parte superior de este folio hay una anotación posterior que dice : «tiene 339 fojas». El manuscrito está escrito a dos columnas y no tiene índice ni prólogo.

\section{Rasgos lingüisticos}

Las dos versiones castellanas ofrecen rasgos lingüísticos diferentes. La contenida en el manuscrito 30037 de la British Library está hecha desde el latín, es muy literal y contiene abundantes errores de lectura o de copia; en cambio, la de fray Vicente de Burgos tiene como base un texto francés acompañado de otro latino, lo que parece indicar que el traductor puso un especial cuidado en conseguir una buena traducción castellana, respetuosa además con la obra latina.

Pero aparte de las diferencias que implica la propia traducción, los dos textos castellanos ofrecen variantes diatópicas significativas. La de fray Vicente de Burgos guarda relación con el oriente peninsular; la presencia de voces del tipo jenebro y genero, que alternan con enebro y enero, plagas, clamando, flamas, los adjetivos invariables dotados de terminaciones masculina y femenina, del tipo vid agresta, la boz febla, las ánsaras, los lobos covardos, el licor dulço, los plurales femeninos y masculinos en -es, ovejes, ministres, la presencia del sufijo -enco, -a, en ombrenca, vermejenca, o-aje en ermitaje, aun tratándose de soluciones minoritarias a lo largo del texto, muestran que la variedad empleada pertenece sin duda al oriente, posiblemente a la zona aragonesa.

De manera paralela el léxico muestra mezcla de elementos aragoneses, catalanes, quizá occitanos en algún caso, más los galicismos atribuibles al proceso de traducción. Entre ellos aved, 'abeto', palabra tardía en Castilla pero documentada en fechas tempranas en aragonés y catalán; caja y cajuela, de nuevo extraños y escasos en castellano medieval pero bien documentados en aragonés y catalán; lo mismo pica, 'pequeña mancha en la piel del hombre y de los animales', mustela, 
'comadreja'12, o garceta, 'cabello, pelo', atestiguado en catalán medieval, aunque de etimología aragonesa ; beçón, 'mellizo' enlaza con el catalán bessó ${ }^{13}$; capel, 'corona de ramas o flores', coincide con el catalán y occitano, al igual que el femenino higa seca, o drapero, frente a trapero del castellano y portugués; taca, 'mancha', es variante bien documentada en occitano, catalán y aragonés ; esquina en el sentido de 'espinazo' se halla en catalán, occitano, francés e italiano; en la misma línea tenemos amortar, 'amortiguar, apagar' ${ }^{14}$, angoxa por 'angustia' ${ }^{15}$, bebraje, 'brebaje, bebida" ${ }^{16}$, devallar, 'bajar o hacer bajar ${ }^{117}$, guastar, guasto, desguastar, deguastar o deguasto ${ }^{18}$, niñeta del ojo 'pupila o niña del $\mathrm{ojo}^{11}{ }^{19}$; riostra, occitanismo representado tardía y escasamente en castellano, es aquí sinónimo de cabrio ${ }^{20}$. Abundan palabras tomadas del catalán, no desconocidas en castellano pero no especialmente usuales o

\footnotetext{
${ }^{12}$ En adelante utilizo BL para la versión del manuscrito 30037 de la British Library y BN para la traducción de fray Vicente de Burgos, Incunable 1884 de la Biblioteca Nacional. «El serpiente que mucho traga beve poco y aborrece mucho el olor de la ruda, y por esto la culebra fuye a la mustela que come mucho la ruda », BN, fol. 265r. Cf. J. Corominas y J. A. Pascual, Diccionario Crítico Etimológico Castellano e Hispánico, DCECH, Madrid, Gredos, 1980-1991, s.v. mustela, donde se atestigua su uso, en el sentido de 'comadreja', en catalán y parte del aragonés y, por el lado occidental, en Asturias y León.

${ }^{13}$ «De las aves [...] Aviene alguna vez que son beçones o dos dentro de un casco y d'estos será el uno mayor que el otro y de más salvaje fación, como Aristótiles dize en el VII de los Animales », fol. 151v. Cf. G. Colón, «La división del romance hispánico », Orígenes de las lenguas romances en el reino de León. Siglos IX-XII, León, 2004, t. I, p. 422.

${ }^{14}$ «Aunque el venino del tiro y de la vípera y de algunos otros serpientes sea caliente los que mueren han grand frío, ca el venino amuerta el calor natural », $\mathrm{BN}$, fol. $112 \mathrm{v}$. Cf. DCECH, s.v. morir, donde se recoge en este sentido como propio de Benasque, Pallars, Arán y occitano antiguo.

${ }^{15}$ Del catalán angoixa ; cf. DCECH s.v. angustia.

${ }^{16}$ La falta de la metátesis característica del castellano recuerda las formas catalanas y francesas que le dieron origen.

${ }^{17}$ El texto dice : «Esquinancia [...] viene de la postema de la garganta y es en tres diferencias, ca en la primera toda la materia es recogida dedentro entre la arteria llamada tracia y el conduto de la garganta en una hoja que es ende. Esta es conocida por el grand dolor que haze el paciente sin hinchazón por defuera y, aunque la boca sea abierta, la persona no vey la hinchazon por dedentro. El enfermo ha fiebres muy agudas y la boz empachada y no puede devallar la bianda. Y tal especie no puede ser guarida, ca mata la persona en un día », fol. 100r. Para el castellano devallar, 'derribar, abatir', del catalán devallar'bajar', cf. DCECH s.v. valle, donde se dice que la forma es rara y ant. en castellano.

${ }^{18}$ Alternan con gastar, desgasto, etc., a lo largo del texto, aunque predominan las formas con ua ; cf. DCECH s.v. gastar.

19 El texto ofrece sistemáticamente niñeta, nunca otra variente del tipo niña, niñita, atestiguadas en castellano; cf. DCECH s.v. niño, niña.

${ }^{20}$ Se usan los dos vocablos para traducir el latín tigna; cf. el apartado dedicado a la traducción y $D C E C H$ s.v. riostra.
} 
populares, como congoxa, congoxoso ${ }^{21}$, feble, 'débil', y los derivados feblez, febleza, febleça, afeblecer, enfeblecer.

Muestra de galicismos que deben atribuirse a la traducción son canilla, 'oruga', escaraviz, 'cangrejo', coldra, 'avellano', chasno, 'roble', evena, 'ébano', fue, 'haya, árbol', fuena, 'fruto del haya', sapin, 'abeto', plastro, plaustro, 'yeso' o el adjetivo fado 'insípido" ${ }^{22}$; vípera, "víbora', puede atribuirse a latinismo, pero también es un posible galicismo. Más sorprendente es que emplee la variante livielso por divieso, cuando las formas con $l$ - suelen asociarse preferentemente al occidente peninsular ${ }^{23}$.

La lengua de la traducción anónima tal y como nos ha llegado nos lleva, en cambio, a la zona situada al occidente del castellano. En realidad, no sabemos a quién atribuir estas características lingüísticas, si al traductor o a un copista. Habitualmente la intervención de los copistas en este tipo de textos es más pasiva, pero es posible encontrar excepciones; lo cierto es que conservamos en un manuscrito del siglo XV una versión que desde el punto de vista lingüístico es anterior ; así parece demostrarlo la presencia de otrie, mais, cedo, fascas, el adverbio $y$, o la apócope en la enclisis del pronombre personal átono. Por lo demás nos inclinan hacia el occidente del castellano rasgos como la palatalización de $\mathrm{N}$ - en $\tilde{n} u d o, \tilde{n} u d o s a$; el mantenimiento de $-M B$ - latino en lombo y lamber, palabras que podríamos atribuir al latinismo del texto, pero que se repiten continuamente como ejemplos del fenómeno en el occidente peninsular ${ }^{24}$; la presencia de selmana junto a semana; las alternancias $l / r$ en grupos consonánticos homosilábicos, con ejemplos como abrandar, grandes, por glande, 'bellota', grutinosa, ombrigo, repreción, apránanlos, fremáticas, añubrado, sobrancos, que traduce el latín subalbida $\mathrm{y}$, en sentido contrario, Cantáblico, flaquente, 'frecuente'; el mantenimiento de $-e$ en céspede, tosse y pece; la epéntesis de - $i$ - en la terminación, nudio; el cierre de vocales finales, estrípitu, aspectu, sexu; el frecuente cierre de las átonas, iscoria, cautirizado, urín, uriniento, rucio o furambre ${ }^{25}$; la pérdida de la $-r$ del infinitivo ante pronombre átono, tornase $i a^{26}$. La mayor parte de estos fenómenos están incluidos entre los rasgos que Menéndez Pidal consideró, hace ya un siglo, generales

\footnotetext{
${ }^{21}$ El vocablo castellano procede del catalán donde congoixa es voz muy usual en la época medieval, a diferencia del castellano.

${ }^{22}$ Algunos de los ejemplos proceden de M. N. Sánchez y E. Jiménez, art. cit., donde pueden hallarse más.

${ }^{23}$ DCECH s.v. divieso.

${ }^{24}$ Las dos palabras han representado hasta nuestros días la lexicalización de un rasgo conservador del leonés ; lamber fue usual en el castellano de la época clásica y hoy llega hasta la Rioja; cf. J. A. Frago, "Léxico preliterario y caracterización dialectal en el dominio leonés », Orígenes de las lenguas romances en el reino de León. Siglos IX-XII, León, 2004, t. I, p. 369 y G. Colón, ibid., p. 404.

${ }^{25}$ Algunos de estos ejemplos y otros parecidos están recogidos en Bartolomé Ánglico, De las partes de la Tierra y de diversas provincias. Las versiones castellanas del libro XV de De proprietatibus rerum, éd. de M. N. Sánchez González de Herrero, Vigo, Editorial Academia del Hispanismo, 2007, p. 19-20.

${ }^{26}$ «La vit [...] sepas que, si non se podase y endereçasse cada año, tornase ía estérile y sin fruto », fol. 191.
} 
al dialecto leonés ${ }^{27}$, algunos de los cuales no han estado tan circunscritos a dicho dominio sino que se han extendido históricamente hacia el oriente, hasta La Rioja y Burgos, por ejemplo ${ }^{28}$. Hay dies ${ }^{29}$ por días, y rege por reja, 'arado' ${ }^{30}$; la variante seía 'sede o silla' 'lugar en que se asienta algo', con pérdida del resultado de - lj- latino, casa bien con soluciones esperables en el dominio leonés ${ }^{31}$. La diptongación coincide en bastantes ocasiones con el castellano antiguo, culuebra, culuebros, mienta, lienta, pero también hallamos casos raros en castellano, como fiégado, fiezes o sollueço. Voces como ginollos, 'rodillas' y mallar, 'majar' son claros dialectalismos en la Baja Edad Media, comunes a los dos dialectos históricos o primarios, asturiano leonés y aragonés. Estas características, en conjunto, nos llevan al occidente del castellano, sin que podamos precisar más ; podemos decir que no se trata de un registro marcadamente o extremadamente occidental, pero sí occidental.

En el terreno léxico, encontramos también formas bien conocidas en el occidente peninsular ${ }^{32}$ como aballar, 'mover', apertar, apierta, por apretar, arramar, 'derramar', arrevezes, 'alternativamente', asin, 'así'33, atropar, 'juntar',

${ }^{27}$ R. Menéndez Pidal, El dialecto leonés, León, El Búho Viajero, Edición conmemorativa 1906-2006, p. 159, 160, 166, 168.

${ }^{28}$ Para el mantenimiento de -MB- en la Rioja y localidades sorianas próximas, J. R. Morala, «De la complejidad interna del castellano en Castilla (y León)», Pulchre, Bene, Recte. Estudios en homenaje al profesor Fernando González Ollé, C. Saralegui y M. Casado (eds.), Pamplona, Eunsa, 2002, p. 955-969. Para selmana en Burgos, cf. DCECH s.v. siete.

${ }^{29}$ « De la fiebre cotidiana [...] en aquestas fiebres comúnmente acontece dolor de la cabeça, mal sabor de la boca, graveza del cuerpo, frío procediente y calor siguiente ; y cada uno de los dies el encendimiento se renueva, que algunas vezes es peor y dóblase », fol. 55v. El cambio as $>$-es caracteriza al asturiano central y ha sobrevivido en algún punto del leonés occidental, concretamente en Sanabria, pero la palabra dies por días es más que habitual en la documentación medieval leonesa.

${ }^{30}$ « Es aún la flor del campo flor así dicho especial porque por sí crece en muchos lugares nin ensulcados con rege nin con estiércol engrosados », fol. 166r ; en la versión latina, que en adelante cito $\mathrm{Tl}$, «crescit in locis incultis nec sulcatis vomere nec stercore impinguatis ». X. L1. García Arias, Gramática histórica de la lengua asturiana, Oviedo, Academia de la Llingua asturiana, 2003, p. 21-22, dice : «Un rasgo común a todo el asturiano es la tendencia a la palatalización de la $-a$ átona en $-e »$. F. Krüger, La cultura popular en Sanabria, Zamora, Instituto de Estudios Zamoranos Florián de Ocampo, 1991, p. 167, recoge relle, 'reja del arado'. J. R. Morala me dice que en Omaña ha oído muchas veces la realización $-a>-e$.

${ }^{31}$ «Animales [...] los que carecen de sangre carecen de coraçón mas tienen alguna cosa en lugar de coraçón en que está la seía de la vida », fol 197v ; grafiado seia, del latín sedīlia, plural de sedīle, de donde seýja en Berceo, cf. DCECH, s.v. sentar, nota 3, y s.v. sel.

${ }^{32} \mathrm{Al}$ decir formas bien conocidas en el occidente peninsular, me refiero a que están documentadas allí en el periodo medieval, y en algunos casos se conservan hasta nuestros días, lo que muestra su arraigo ; no hablo de palabras exclusivamente occidentales, restricción por otro lado muy difícil de establecer, dado el estado de nuestro conocimiento de los diatopismos medievales.

${ }^{33}$ Aunque asin es forma vulgar muy extendida aún hoy por todo el dominio, en la Edad Media lo habitual es assí, así en castellano ; también en gallego predomina assí, aunque assín no es inaudito, según $D C E C H$ s.v. así. 
órreo, 'granero', solombra, 'sombra'; o formas compartidas con el castellano antiguo, como bosar, 'vomitar', carmenar, desganar, 'matar', enanchamiento, enanchar, engurriarse, 'arrugarse', enziva, 'encía', o pendar, 'peinar'. Algunas de las voces que usa figuran en el $\mathrm{DCECH}$ como atestiguadas en Santander, aunque es posible que ocupen o hayan ocupado un área más extensa; se trata, entre otras, de corruscación, 'relámpago' ${ }^{34}$, molilla por molleja, como traducción de 'hígado'35, y bren, 'salvado's6.

Las muestras, relativamente abundantes, de la concordancia conocida como 'neutro de materia' apoyan también esta procedencia centro-occidental norteña, pues se trata de un fenómeno atestiguado hoy en una amplia franja que va desde la cornisa cantábrica hasta Toledo ${ }^{37}$. Entre los ejemplos tenemos :

La goma que sale de los almendros, mezclado al bever, ayuda a los que echan sangre (fol. 151r).

La flema, uno es natural y otro non natural; la natural es frío y húmido, en el color blanco, en la sustancia cárdeno, en el sabor insípido (fol. 14r-14v).

Cobre [...] Fazen vasos de diversas maneras fermosos, semejantes en su novedat a oro, mas poco a poco van perdiendo el color primero, y después fázese uriniento. En tales vasos puesto el vino o vianda, fazen sabor abominable, si mucho en ellos se guarda. Los alcohores, que son melezina para los ojos, se guardan en ello mucho bien y de la fortaleza del metal se aguzan (fol. 132v).

Otrosí dize él que muchas vezes se fallan unas arañas en los cañales de las abejas que chupan la miel y lo corrompen (fol. 204r).

\footnotetext{
${ }^{34}$ «Corruscación, segunt Aristótiles, aprehende el fulgar, que es aquel resplandor, y esta atal es dicha inpropia porque propiamente es dicha corruscación; es apareción súbita de vapor subtil enflamado esvaneciéntese en el aire, sin descendimiento a tierra. El relámpago es fuego subtil más grueso que la corruscación o resplandor a tierra », BL, fol. 82r. La traducción de fray Vicente de Burgos usa relámpago. DCECH s.v. coscorrón, recoge santand. corruscar, tarruscar, 'abrasar'.

${ }_{35}$ «Del cabrito [...] La su molilla, si la comen, dize sanar la agudeza tardinera de los ojos a estos que padecen enfermedades que llaman lagaña », BL, fol. $219 \mathrm{v}$, donde molilla traduce el latín iecur. DCECH, s.v. molleja, cita molilla en Santander y norte de Burgos, tomado de García de Diego.

36 «Fázese farina propiamente cuando el frumentum entre las muelas es muy bien quebrantado ; mas bren llaman aquello que de la sustancia del meollo es apartado, ca cuando la flor del meollo es apartada del bren o de la corteza, estonces los gramáticos le llaman simila o similago; y dízese por otro nombre pole o polle, de donde desciende hec pollenta, quiere dezir poleada, y hoc polumentum desciende de pulte, como dize Isidro », fol. 164v. En las dos apariciones bren traduce el latín furfure. El $D C E C H$, s. v. bren, lo recoge como variante antigua y santanderina.

${ }^{37}$ I. Fernández Ordóñez, «El neutro de materia hispánico », Revista de Historia de la Lengua Española 1, 2006, p. 68.
} 
Son especialmente abundantes los latinismos del tipo aer, 'aire', arista, 'espina del pescado', ceptros, 'cetros, bastones', coxa, 'muslo', cotis, 'piedra aguzadera', dolo, 'astucia, engaño', evanecer, 'desaparecer', flama, 'llama', íbice, 'cabra montés', hínulo, 'mulo joven', lacerto, 'músculo', moto, 'movimiento', desiderio, necto, nomen, similitudo, simplices, etc.

Es interesante la comparación del léxico empleado por las dos versiones porque muestra diferencias numerosas y significativas. En primer lugar, es frecuente que la versión anónima mantenga el latinismo, o una forma adaptada próxima a él, mientras que la traducción de fray Vicente de Burgos usa una forma o una expresión romance; por ejemplo, la primera contiene agüerantes en paralelo al latín auguriantes $^{39}$, o ferax 'feraz', que la segunda, mucho menos literal, omite. Son muestra de la diferencia los siguientes paralelismos: colecterales / acesorios o ayuntados a los principales ${ }^{40}$; comulga / se haze común; confablación / conversación y mucha habla; cuatropeya, cuatropea / animal de cuatro pies; edómadas ${ }^{41}$ / semanas; enardece ${ }^{42}$ / inflama; refocilar / pacer; residuo / lo que queda; rupes / rocas o peñas; turbones (de aire) / aire turbio.

Teniendo en cuenta que estamos ante dos traducciones de cronología diferente, es esperable que la primera contenga variantes más antiguas o que dejaron de emplearse en fechas más tempranas, del tipo entrepieços (embargos y entrepieços) / obstáculos ; enxerir / entrar dentro ; espessamente / muy continuo ; golfin (los golfines y las ocas) / dolfin (nin ballenas nin dolfines); siesta / grand calor.

Las diferencias pueden deberse al uso de diatopismos, de carácter occidental en el caso de la traducción anónima, pendes / peines ; solagar / asolar; solegar / meter dentro; vera, 'orilla', sin paralelo exacto en la traducción de fray Vicente de Burgos ${ }^{43}$. En esta, en cambio, los diatopismos son de carácter oriental, mérula /

\footnotetext{
${ }^{38}$ Aparecen con frecuencia intercalados en contextos castellanos, del tipo «Del oído [...] el medio diferente es aer ferido y la entención de la ánima », BL, fol. 8v.

39 «Otros son que tienen el perro por rey, los cuales por el su movimiento agüerantes fazen lo que parece », BL, fol. 118r. «Los otros han un perro por rey y, segund el movimiento del rey, ellos entienden lo que deven hazer», BN, fol. 185r. En el texto latino, «cuius motu auguriantes faciunt quod videtur ». En paralelo, BL agüerear frente a adevinar en BN.

${ }^{40}$ El primer ejemplo de cada pareja corresponde a la traducción anónima, es decir a BL; el segundo a la de fray Vicente de Burgos, BN.

${ }^{41}$ « Por ocho edomadas de años », BL, fol. $216 \mathrm{r}$; «por el espacio de VIII semanas de años », BN, fol. 183v. Según $D C E C H$ s.v. siete, De $\varepsilon \beta \delta o \mu o \varsigma$, equivalente de séptimo, deriva $\varepsilon \beta \delta o \mu \alpha ́ \varsigma$,

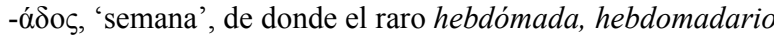

${ }^{42}$ Cf. DCECH s.v. arder, donde se duda de si enardecer, tardíamente documentado, es formación romance o latinismo.

${ }^{43}$ «Las grullas, con boz de pregón, demandan la vera porque fuelguen y, cuando se sientan, ordenan vegillas para su guarda, porque las otras seguro fuelguen », BL, fol. 90r. En BN, « las grullas decienden a tierra a la voz de su governador por reposar y, cuando son deciendidas, ordenan las más viejas por guarda de las otra, porque más seguramente puedan reposar », fol. $157 \mathrm{v}$. DCECH s.v. vera, dice que es palabra tomada posiblemente del portugués beira, rarísima en castellano, salvo como término empleado por gente de mar.
} 
merle $^{44}$; similia / sémola ; yermo / ermitage ; zizania, lolio / viraga ; sembrada / simencera.

Finalmente y al margen de las explicaciones que en cada caso podrían considerarse, valgan los siguientes ejemplos como muestra de la variación léxica de las dos traducciones : alberca / picina ; arregañar / abrir; ataleadores / alcaides ; aves de robo / aves de caça; cachoncillo / perrillo; chirlador / burlador; cojones / generativos ; collado / cuesta ; confirgamiento / el frotar; se destorpan / se puran; ensobervecerse / repostrar ${ }^{45}$; resolgar / resollo; governallo / guvierno; roca guijarreña ${ }^{46}$ / roca muy alta ; regañar / gruñir ; repilado / terrible ; sugar, 'chupar' / bever (la sangre), etc., además de multitud de ejemplos donde no se pueden establecer oposiciones directas, bien porque las traducciones no son paralelas ${ }^{47}$, bien porque una de las dos evita determinados fragmentos, contextos o palabras, como en el caso de golmiar $^{48}$, sin correspondencia en la versión de fray Vicente de Burgos.

\footnotetext{
${ }^{44} \mathrm{La}$ forma merle alterna con melre en $\mathrm{BN}$ para designar al ruiseñor y coincide con formas antiguas del catalán y del francés, frente a la $-a$ final que muestran las variantes castellanas antiguas mierla, mirla; cf. DCECH s. v. mirlo. Además del latinismo mérula, BL usa también filomena, por ejemplo al hablar de las aves que tienen cantos graciosos, como filomena o oropenda, fol. $84 \mathrm{r}$, que corresponde en BN a melres y ruiseñores. P. Montero Curiel y M $\mathrm{M}^{\mathrm{a}}$. L. Montero Curiel, El léxico animal del Cancionero de Baena, Madrid, Iberoamericana, 2005, p. 247-250, recogen filomena y filomela como "sinónimos ennoblecidos de ruiseñor» y aceptan la explicación del $D C E C H$ en el sentido de que ambas variantes se relacionaron poéticamente con el ruiseñor, "por confusión con el nombre propio de mujer».

${ }^{45}$ Los fragmentos resultan interesantes por ser repostrar voz poco documentada. Lo que dicen es : «Es la propiedat de las siervas, así como dize Rabí, contra sus dueñas encruelecerse cuando non ha miedo y contra el señorío de los mayores ensobervecerse por coraçón finchado, así como aparece en Agar, en el Génesi, a los XVII capítulos », BL, fol. 41v. «La moça ha esta propiedad de se levantar contra su señora y de repostrar si su señor no la castiga, assí como leemos de Agar, la servidora de Sarra que, por las malas respuestas que dava a su señora, Abraham la echó fuera de casa, como parece en los XXI capítulos del Génesis », BN, fol. 83v. Tl usa insolescere y la versión francesa de soy esleuer en orgueil.

${ }^{46}$ La grafía es gigarreña.

${ }^{47}$ "Los andantes o mareantes en las noches », BL, fol. 73v / «Los que caminan de noche o por mar o por tierra », BN, fol. $138 \mathrm{v}$.

${ }_{48}^{4}$ Caribdi es un lugar en la mar, fondo y tuerto, donde fazen remolinos y, por tanto, las naves que allí allegan tráhelas en sí y sórvelas y solégalas; tres vezes en el día levanta tempestad y asorve, ca las aguas que recibe porque las trague, golmia, porque arriba las reciba, segunt Isidro », BL, fol. 101v. Compárese Etym. XIII, 18, 5, Charybdis [...] Ter autem in die erigit fluctus, et ter obsorbet; nam accipit aquas ut vomat, vomit ut rursus accipiat; es decir, 'tres veces al día encrespa las aguas y otras tres las absorbe; y es que engulle las aguas para vomitarlas y las vomita para engullirlas de nuevo'. DCECH, s.v. gola, recoge golosmear, y por cruce con gazmiar, golismar; el mismo cruce, añade, se da en los riojanos golmajo, 'goloso', golmajear, 'golosinear', etc., y a la misma familia pertenece golmiar, posible cruce de golosinear y gazmiar, aquí con el sentido de 'engullir'.
} 


\section{La Traducción}

Desde el punto de vista lingüístico, la versión anónima sigue el latín de manera paralela, mimética en muchos casos, palabra por palabra, incurriendo con relativa frecuencia en errores; ciertamente no tenemos la seguridad de que algunas malas lecturas o párrafos sin sentido tengan su origen en la traducción y no en la copia, en alguna de las posibles copias posteriores a la traducción, pero el carácter de muchas de las desviaciones apunta hacia la traducción. Basta comparar el siguiente párrafo del capítulo de los huevos en castellano y en latín :

En las regiones pónense en el estiércol al sol y cumplen, así como en Egipto. Y en algunos lugares en plumas calientes, así como en una cibdat, la cual compuso uno que llaman portitor y dixo que continuó el puerto fasta que de aquellos huevos se sacavan los pollos. Algunas vezes ponen los huevos en vasos calientes (BL, fol. $264 \mathrm{v})$.

In calidis autem regionibus ponuntur in fimo ad solem et completur, ut in Egipto. Et in quibusdam locis in plumis calefactis, sicut in quadam civitate quidam potator composuit ova sub pulvinari et dixit quod continuavit potum quousque ex illis ovis pulli extra hebantur. Aliquando etiam ponuntur ova in vasis calidis (fol. 312).

Compárese la traducción de la versión de fray Vicente de Burgos :

En algunas regiones calientes ponen los huevos en estiércol al sol y ende se crían los pollos como si la gallina los sacase del casco, assí como en Egipto. Y en algunas otras tierras los ponen entre plumas calientes, como cuentan algunos de un grand bevedor que puso los huevos embueltos en pluma en su lecho y juró que no cesaría de bever hasta que los pollos saliesen, y dentro de poco tiempo salieron. Otros los ponen en vasos calientes (BN, fol. $313 \mathrm{v})$.

En general sigue el texto latino palabra a palabra, saltando casi continuamente palabras o pequeños fragmentos, como puede comprobarse en el siguiente párrafo :

Malenconía es humor espesso y grueso, de la fez y de la turbulencia de la sangre engendrado ; y es dicho cólora negra del animal, ca su color declina a negrura. Y es una natural y otra non natural. La natural es fría y seca, que se faze en la sangre así como la fez en el vino, y su sustancia es espessa y de tierra, el sabor del cual entre la dulçura y amargura está. Y aqueste se departe en dos partes ; una va con la sangre y penetra consigo a los miembros malencónicos enbiaderos, y aún ayuda porque es la sangre espessa nin fuya por su liquidat la digistión. Otra parte es enbiada al vaso para alimpiar todo el cuerpo y para criar esse vaso (fol. 14r-15v).

Melancolia est humor spissus et grossus ex fece et turbulentia sanguinis generatus. Et dicitur a melon, quod est niger, et colon, quod est humor; inde dicitur melancolia quasi niger humor. Unde a physicis colera nigra nuncupatur. Nam color eius declinat ad nigredinem. Est autem melancolia alia naturalis, alia innaturalis. Naturalis frigida est et sicca, que fit in sanguine, sicut fex in vino habet generari, cuius substantia est spissa et terrestris, cuius sapor inter dulcedinem et ponticitatem existit vicinus accipienti. Hec melancolia in duas partes habet dividi, quarum una 
remanet cum sanguine et penetrat secum ad membra causa necessitatis et iuvamenti. Fuit enim necesse ut cum sanguine misceretur, ut aptificaret sanguinem ad membra melancolica nutrienda. Iuvat etiam sanguinem, quia inspissat eum, ne sui liquiditate subterfugiat digestionem. Secunda vero pars transmittitur ad splenem etiam propter necessitatem et iuvamentum. Necesse enim fuit hoc propter mundificationem totius corporis et propter nutrimentum ipsius splenis ${ }^{49}$.

O en :

Onde ángel nombre es de oficio y non de natura. Espíritu es el ángel, mas cuando es embiado de Dios, entonce dezimos propiamente ser ángel (fol. 2r-2v).

Unde angelus nomen est officii, non nature. Spiritus autem semper est angelus, sed quando a Deo mittitur, tunc primo proprie angelus nuncupatur ${ }^{50}$.

Mantiene frecuentes participios de presente trasladados de la versión latina:

Otrosí las mugeres usántesse mucho non han su camisa mucho (fol. 14r).

Mulieres nimis se exercentes et sepius moventes non multum menstruant ${ }^{51}$.

$\mathrm{Y}$ tal tierra, por la acción del calor, las partes que son más delgadas consumiente, y las que son más delgadas endureciente, múdalas en ladrillo (fol. 131v).

So tal diferencia del humor enseñoreántese y del calor faziente y la sustancia digiriente y mudante en todos los sobredichos se engendra diferencias de sabor (fol. $146 \mathrm{v})$.

El vino blanco o negro o tinto es más caliente de todos; el blanco empero es más húmido que el tinto por la subtileza y aguosidat enseñoreántese en él (fol. 194r).

Todo animal teniente dientes cerrados es goloso y batalloso, así como parece en el can y lobo cerval, osso, león (fol. 198r).

Otrosí las abejas amelantes matan los machos empecientes a ellas y los reis malos cuando a ellas non bien rigen (fol. 206v).

Mantiene con frecuencia el verbo al final de la frase :

Dios simple es, non ha cosa que más simple sea que Dios, ninguna quantidat ha, muy simple es (fol. 2r).

Uno es el cobre y el azero, ca ambos de una piedra, por cozimiento de fuego, salen (fol. 136r).

Esta yerva conocen los canes y cómenla cuando se quieren purgar, mas, así como dize Plinio, así fazen esto cautelosamente que malavés puede esto a la noticia de los ombres venir (fol. 167v).

Primero la comadreja la yerva ruda aunque amarga come, y así, por virtud del çumo de la yerva armada agora, a enemigo sin miedo acomete y vence (fol. 208r). palabras :

Hace traducciones literales, en definitiva no traducciones, de muchas

Los ojos, como dize sant Isidro en el libro $\mathrm{X}^{\mathrm{o}}$, capítulo segundo, por ende son dichos ojos por aquellos las coberturas de otros cubran, nin algunas incidentes injurias los

${ }^{49}$ Cf. Bartholomaeus Anglicus, éd. cit., t. I, p. 239.

${ }^{50}$ Ibid., p. 105.

${ }^{51}$ Ibid., p. 234. 
dañen ofendiéndolos, o porque lumbre ascondido o secreto puesto entre ayan (fol. $18 \mathrm{r})$.

Oculi, ut dicit Isidorus in libro XI, capitulo II, quasi occulti sunt dicti quia esos ciliorum tegmina occultant, ne qua incidentis iniuriae offensione ledantur, sive etiam quia occultum lumen et secretum positum intus habeant ${ }^{2}$ (fol. $39 \mathrm{r}$ ).

Sequedat $[. .$.$] ha otros secundarios efectos muchos, así es, en espisión, exasperar y$ retardar el movimiento y desgastar, destruir y mortificar (fol. 11v).

Siccitas [...] secundarios autem effectus habet multos, sicut est inspissare, exasperare, motum retardare, consumere, destruere, mortificare ${ }^{53}$.

Item necesario es el motu medio, porque si se mueve la cosa vista por el ímpetu grande, la vista confonderse ía; y por el moto (grande) [pequeño] y continuo, dispergirse ia (fol. 8r).

Item, necessarius est motus mediocris; si enim moveretur res visa ex multo impetu, visus confunderetur et ex motu nimio et continuo dispergeretur ${ }^{54}$.

Germen, como dize Isidro, es preñante planta dicho o sorquillo ${ }^{55}$ (fol. 167r).

En definitiva, se trata de una traducción abreviada, más en unos libros que en otros, pero resumida en general, muy apegada a la fuente, que reproduce estructuras y vocablos de la lengua de partida, en este caso el latín, y contiene en la versión que nos ha llegado desviaciones de traducción o de copia que en ocasiones dificultan o impiden la lectura.

La versión de fray Vicente de Burgos, en cambio, es más cuidada. Habitualmente se dice que está hecha a partir de la francesa de Jean Corbechon ${ }^{56}$, lo que es en parte cierto, pero no del todo, porque el traductor utilizó también una fuente latina, al menos en buena parte de su trabajo ; así lo demuestran la presencia de pequeños fragmentos, nunca extensos, que Corbechon eliminó y el uso de vocablos, especialmente latinos y relacionados con la etimología, omitidos también por el traductor francés, pero presentes en la versión castellana ${ }^{57}$; en ocasiones es evidente que sigue el texto latino. Se trata de ejemplos del tipo:

\footnotetext{
${ }^{52}$ La versión castellana traduce entre por intus 'dentro'. El texto latino sigue de cerca Etimologías XI, 1, 36, Oculi vocati, sive quia esos ciliorum tegmina occulant, ne qua incidentis iniuriae offensione laedantur, sive quia occultum lumen habeant, id est secretum vel intus positum. Cf. Isidoro de Sevilla, Etimologías, Éd. et trad. de J. Oroz Reta et M. A. Marcos Casquero, Madrid, Biblioteca de Autores Cristianos, 1993.

${ }^{53}$ Cf. Bartholomæus Anglicus, éd. cit., t. I, p. 215.

${ }^{54}$ Ibid., p. 167.

${ }^{55}$ Etimologias XVII, 6, 22, Germen dicimus surculum praegnantem.

${ }^{56}$ B. Beyer de Ryke, «Le miroir du monde : un parcours dans l'encyclopédisme médiéval », Revue Belge de Philologie et d'Histoire 81, p. 8 . Texte intégral, http ://dev.ulb.ac.be/philo/urhm/pdf/miroir.pdf.

${ }^{57}$ Cf. Bartolomé Ánglico, De las partes de la Tierra y de diversas provincias. Las versiones castellanas del libro $X V$ de De proprietatibus rerum, éd. de M. N. Sánchez González de Herrero, Vigo, Editorial Academia del Hispanismo, 2007, p. 21-23 y M. N. Sánchez y E. Jiménez, art. cit., donde pueden encontrarse otros ejemplos.
} 


\begin{abstract}
Alabastro [...] el más provado y más fino es el de India. Esta piedra llama Diascórides nicomar y dize que mucho vale para aver vitoria y dize que engendra y guarda amistança (fol. 199v, contexto al que corresponde en francés,

Alebastre [...] mais y vault mieulx en Inde. Et vault a avoir vittoire contre ses ennemys sicomme dit Dyascorides ${ }^{58}$.
\end{abstract}

En cambio, el paralelo en este caso se halla en el texto latino, donde leemos :

Alabastrum [...] sed probatissimus de India transportatur. Hic lapis Dyascoride
nicomar dicitur et dicit valere hunc lapidem ad victoriam obtinendam et dicit etiam
que generat et conservat amiciciam.

En el comienzo del capítulo del betún, en el libro XVI, leemos :

Betum es un terrón viscoso o lodoso que mayormente es en los prados engendrado. Hay una tierra lodosa, segund cuenta Isidoro en el XVI, capítulo II, cerca del lugar llamado Asfalto ${ }^{59}$ en Judea, cuya natura es ardiente y nacida como fuego y es de tan grand fuerça en tenerse que ni con agua ni con hierro puede ser después corrompida, salvo con la sangre mostruosa (fol. 201v).

En el texto francés :

Ciment est appelle en latin bitume et est une mocte de terre limoneuse et glueuse qui croist en aulcuns mares, especialement, selon Isidore au XVI livre, pres de la mer Morte, qui est en Judee, on trouve ung ciment si ardant et si tenant que il ne peut estre despecie ne par feu ne par eaue, mais tant seulement par una matiere secrete que na fault pas nommer pour l'onneur des dames.

De nuevo el texto castellano parece apartarse del francés y aproximarse al latín :

Bitumen est terra a gleba limosa et viscosa in locis precipue palustribus generata. Est autem secundum Isidorum, libro XVI, capitulo II, terra glutinosa que iuxta lacum Asphalti in Iudea reperitur cuia natura est ardens et igni cognata, et est tante tenacitatis que nec aqua nec ferro rumpitur, sed solum sanguine menstruali.

El comienzo del capítulo 167 del libro XVII sigue el latín, recuperando un breve fragmento que falta en la versión francesa :

Las riostras o cabrios son unos maderos o fustes que desde la pared de la casa están levantados fasta a la cumbre o cavallillo del techo para lo sostener, y están puestas

\footnotetext{
${ }^{58}$ A falta de una edición crítica y completa del texto francés, sigo el I-2202 de la Biblioteca Nacional de Madrid. Des propriétés des choses, en français, par Jean Corbichon. Lyon, Jean Siber, de finales del siglo XV. Para el latín en los libros en que aún no hay edición crítica, es decir del V al último, con la excepción del XVII, el I-2456 y el I-2292

${ }^{59}$ En el texto, Alphabeto.
} 
de las paredes a la cumbre en tal manera que hazen rincón de cada cabo. La riostra o cabrio en latín se llama tignum, que es dicho de tegendo, que quiere dezir cubrir, o de tegula (fol. 246v).

Tigna sunt ligna que a parietibus vel muris usque ad cacumen edificii sunt erecta supportantia totum tectum ad modum coni vel piramidis sursum tendunt et paulatim se inclinantia ad alterutrum in cacumine mutuo se contingunt. Et dicuntur tigna a tegendo vel a tegula ${ }^{60}$.

Les chevrons sont en latin appelles tigna pource sont ils cy mis [...].

El hecho de que el traductor recurra a la comparación de dos versiones sería indicativo de la preocupación de fray Vicente de Burgos por ofrecer una texto riguroso a la par que fiel a la fuente, preocupación paralela en cierta manera a la del propio Jean Corbechon, pues distintos estudiosos han puesto de manifiesto la calidad de su traducción al francés ${ }^{61}$. En todo caso no se trata de una novedad ni de un modo de trabajo aislado, pues en estas fechas son muy frecuentes las llamadas versiones en cadena, en palabras de María Morrás; el fenómeno se manifiesta de dos modos distintos pero relacionados entre sí. Por un lado se toman como base de la traducción versiones intermedias de la obra que se traduce; en el caso de Castilla las traducciones de textos latinos se basan en alguna de las preexiententes en otros romances, como el catalán, el italiano o el francés; por otro lado, se revisan versiones antiguas, actualizando la lengua y cotejando de nuevo en muchas ocasiones el texto romance con el original latino, para comprobar su exactitud ${ }^{62}$. Lo que hizo nuestro traductor no fue más que sumar las dos actuaciones en su trabajo.

Fray Vicente de Burgos sigue en muchas ocasiones el texto francés palabra a palabra, pero en general su traducción posee una autonomía con respecto a este muy superior a la del texto anterior; la actitud del traductor es diferente, posiblemente su conocimiento de las lenguas de partida era superior, y no olvidemos la cronología, pues el nivel de las traducciones fue más exigente a medida que avanzaba la Edad Media.

Desde luego no faltan traslados automáticos, la no traducción, pero su número es notablemente inferior al de la versión anónima; entre ellos se halla Apellea :

Bitinia es una provincia por sí, como Isidoro dize, que es de Asia la Pequeña [...] Y en el tiempo pasado fue nombrada de diversos nombres, ca algunos la llamaron Apellea Biricia $^{63}$ y otros Midonia y después fue dicha Betimia (fol. 182r),

que reproduce el francés «elle fut jadis appellee Biricie», donde appellee se ha interpretado como parte del nombre propio.

\footnotetext{
${ }^{60} \mathrm{Cf}$. Bartholomæus Anglicus, éd. cit., t. I, p. 227.

${ }^{61} \mathrm{~B}$. Ribémont, Le Livre des propriétés des choses. Une encyclopédie au XIV siècle, Paris, Stock, 1999, p. 38.

${ }^{62}$ M. Morrás, «El debate entre Leonardo Bruni y Alonso de Cartagena : las razones de una polémica », Quaderns. Revista de Traducció 7, 2002, p. 34-35.

${ }^{63}$ En el texto latino, prius Bericia est dicta; en Etimologías, XIV, 3, 39, de donde procede, prius Bebrycia dicta.
} 

notable.

Aun con todo, la diferencia de calidad en favor de fray Vicente de Burgos es

En lo que sí parecen coincidir los dos traductores es en la contribución al texto que ofrecen, pues los dos intervienen, con la finalidad, suponemos, de facilitar la lectura y la comprensión. Recordemos que se trata de una actitud muy extendida en las traducciones medievales, pues en aquella época, a diferencia de lo que sucede en nuestros días, no había conciencia de fidelidad absoluta al texto, ni siquiera al literario, como obra acabada que pertenece a un autor. Los traductores gozaban de la libertad de intervenir para ampliar el texto o reducirlo, para glosarlo, explicarlo, o para añadir consideraciones de índole moral, para adaptarlo en definitiva a un público que había que instruir; y esto incluso en los frecuentes casos en los que en apariencia el traductor parece respetar escrupulosamente la fuente al traducir palabra por palabra ${ }^{64}$.

Por ello encontramos aclaraciones de vocablos, especializados o no :

Las vexigas $[\ldots]$ son alguna vez muelles y blancas por ser de materia flemática y otras vezes ásperas y duras y puñentes por ser de la cólera que es entre cuero y carne $\mathrm{y}$ abren el cuero por su agudeza y hazen levantar muchas otras vexigas pequeñas como el grano del mijo, que nós llamamos sarampión (BN, fol. 111r).

En Francia ay muy ricas piedras para edificar y mayormente en la tierra al torno de París, do es el plaustro, o yelso que nós llamamos comúnmente, que es blanco de su natura $(\mathrm{BN}$, fol. 186r).

Del cartíllago, que es la ternilla. Cartillago en latín es dicha ternilla de los huesos, y llámase así por razón que por el abto ligero non ha dolor mientra que la fieren, así como aparece en las narizes y en las orejas y en los cabos de las cuestas, ca todas las cosas de ternilla son más duras de carne y de huesos más muelles (BL, fol. 36r).

Vedelium [...] La su gota es mucho apretadiz y traediz, segunt dize Diascórides y, por ende, así como se dize en el Plateario, repuna a la disintería, que es fluxo de sangre, fecha de aguda materia $(\mathrm{BL}$, fol. $154 \mathrm{v})$.

Frecuentemente encontramos la presencia de sinónimos unidos mediante la conjunción $o$ :

De los pardales o gorriones y de sus propiedades. Capitulo XXXIII. Los pardales en nuestro lenguaje, en latín son paseres llamados, y son assí dichos por ser pequeños y menudos, segund dize Isidoro (BN, fol. 160v).

Dos species o maneras hay de peras, la una es salvaje o agresta y la otra es doméstica o ortelana (BN, fol. 236v).

Otrosí entre el árbol y la su fruta es un retenimiento por el cual la fruta se allega al árbol [...] mas en fin, la fruta madurada y traído devida quantidat, sécasse aquel retenimiento o peçón o podrece y entonce de ligero cae la fruta (BL, fol. 150v).

La figuera de Egipto es árbor muy fértil, semejante al moral en la grandeza y en las fojas $[. .$.$] y tiene semejança en la raíz con el álamo o tiemblo y en las fojas con la$ oliva (BL, fol. 163r).

${ }^{64}$ C. Buridant, «Translatio medievalis. Théorie et pratique de la traduction médiévale », Travaux de Lingüistique et de Litterature XXI, 1, 1983, p. 117-121. 
$O$ puede introducir también una aclaración :

La cáscara se rompe algunas vezes después de los XIIII o XX días, como parece en las gallinas y entonce son los pollos en su generación complidos. Aviene alguna vez que son beçones o dos dentro de un casco y d'estos será el uno mayor que el otro y de más salvaje fación $(\mathrm{BN}$, fol. 151v).

En alguna ocasión la explicación no es correcta, como sucede con la versión anónima cuando trata del abeto :

Capítulo V. De abies. Abies es nombre de árbol que dizen faya; dízese así de eundo, por ir, que sobre todos árboles va alliende y en alto se estiende (BL, fol. 151r), que da cuenta del latín:

De abiete. Abies nomen est arboris sic dicte ab eundo eo quod prae ceteris arboribus longe abeat et in altum se extendat.

Es decir, se trata del abeto, aunque el texto lo identifica erróneamente con el haya; unas líneas más adelante habla directamente de la faya donde el texto latino dice abies.

La misma equivalencia errónea se encuentra en el Glosario del Escorial ${ }^{65}$ y es posible que no sea casualidad, pues esta versión coincide con dicho glosario en la identificación de panthera y lobo cerval, noctiluca y luziérnega, limax y caracol, virgultum y vergel, saltus y silva con sierra, cirogrillo y conejo, etc., las dos últimas también de difícil justificación ${ }^{66}$; esto no significa necesariamente que el traductor usara el glosario en cuestión, pues debieron de circular bastantes muy semejantes, con equivalencias análogas, en la Baja Edad Media por toda la Europa occidental; lo que muestra es que recurrió, como debió de ser habitual en las etapas primeras sobre todo, al empleo de glosarios de la época para llevar a cabo su trabajo de volcar al castellano una amplia serie de conocimientos y voces que se habían transmitido hasta entonces, y en parte se seguían transmitiendo, fundamentalmente en latín.

\section{María Nieves Sánchez González de Herrero Universidad de Salamanca}

\footnotetext{
${ }^{65}$ En $D C E C H$, s.v. abeto, tanto este error como la tardía aparición del vocablo abeto en castellano se explicarían por tratarse de un árbol casi exclusivo del Pirineo

${ }^{66}$ A. Castro, Glosarios latino-españoles de la Edad Media, Madrid, C.S.I.C., 1991, p. XII, LVI, 191, 282, 288 y 311.
} 